\title{
SEEING PEOPLE AND KNOWING YOU: PERCEPTION, SHARED KNOWLEDGE, AND ACKNOWLEDGMENT
}

\section{STINA BÄCKSTRÖM}

Åbo Akademi University

\begin{abstract}
This article takes up the proposal that action and expression enable perceptual knowledge of other minds, a proposal that runs counter to a tradition of thinking that other minds are special in that they are essentially unobservable. I argue that even if we accept this proposal regarding perceptual knowledge, there is still a difference between knowing another person and knowing other things. I articulate this difference by pointing out that I can know another person by sharing knowledge with her. Such sharing is expressed in the use of the second-person pronoun. Thus, I argue, other minds are indeed special as objects of knowledge, but not in the way the tradition has supposed.
\end{abstract}

\section{INTRODUCTION}

Consider a non-verbal, facial expression of emotion, such as Peter's joyful smile as he plays with his newborn baby. Such an expression enables knowledge of Peter's state of mind; by seeing the smile on Peter's face, a suitably equipped person can come to know that Peter is enjoying playing with his baby. In the epistemological tradition (in particular in its empiricist strand), knowledge of another person's thoughts or feelings has been taken to constitute a problem separate from knowledge of the external world: one that remains to be solved even if we manage to properly account for and vindicate our knowledge of the external world generally. In according the so-called 'problem of other minds' such a special status, the thought that we don't literally experience, see, or observe another person's state of mind has been an important assumption. On this 
assumption, whatever kind of knowledge an expression such as Peter's smile can yield, it cannot be perceptual or observational knowledge. ${ }^{1}$

This assumption also has a long history of being questioned. Recently, we find people who oppose this tradition of thinking about the epistemology of other minds and directly challenge its supporting assumption by claiming that actions and expressions of mental states precisely enable perceptual knowledge of the minds of others. Now, I will argue that the claim that actions and expressions can afford perceptual knowledge of other minds needs to be coupled with an acknowledgment of a difference between perceptual knowledge gained from seeing a person's action or facial expression, and perceptual knowledge of other kinds of object. I want to resist the assimilation of knowledge of other minds to knowledge of the external world generally.

The tradition has it that other minds present their own epistemological conundrum. I want to articulate what I take to be an insight in this tradition, while not preserving the central thesis of the tradition. I join recent authors in rejecting the assumption that we cannot see, observe, or experience the mental states of others, but I shall argue that this is not the end of the story. There is nevertheless something special about knowing another person's state of mind by seeing him perform intentional actions or express his states of mind, such as seeing Peter's delight in his face.

What is special, I will suggest, is that perceiving another person's action or expression opens a person up to a form of knowledge which is not simply one-sided, but mutual or shared. Such knowledge is manifested by utterances in the second-person form, such as 'You're really enjoying this, aren't you?' When I know what someone is thinking or feeling on the basis of his expressions - such as when I know that Peter is enjoying playing with his baby from seeing his happy smile this judgment contains the basis for me to address Peter (as 'you') and thereby shift my knowledge of him into a new register. This new register is what I'm interested in outlining in this paper. My suggestion will be that knowledge from action or expression is a first step towards a meeting of minds; it is not merely one mind's encounter with an object of knowledge.

${ }^{1}$ In this paper I will not make a distinction between perceptual and observational knowledge. I will, rather, treat these notions as equivalent. 


\section{WE CAN OBSERVE OTHER MINDS: ACTION AND EXPRESSION}

The thought that the minds of others are essentially unobservable is a recurring theme in the epistemological tradition, especially within empiricist epistemology. Other minds are not observed but rather inferred, is the slogan. We see this notion in Russell's Human Knowledge Its Scope and Limits, where he, embracing the classical argument from analogy, says that,

The behaviour of other people is in many ways analogous to our own, and we suppose that it must have analogous causes. What people say is what we should say if we had certain thoughts, and so we infer that they probably have these thoughts. (Russell 1948: 501-502)

A similar and more recent formulation can be found in Paul Churchland's Matter and Consciousness, where he says,

It is of course by observing a creature's behavior, including its verbal behavior, that we judge it to be a conscious, thinking creature - to be 'another mind'. From bodily damage and moaning, we infer pain. From smiles and laughter, we infer joy. From the dodging of a snowball, we infer perception. (Churchland 1988: 67)

We also find this theme as a theoretical assumption in empirical psychology - it figures as a prominent motivation in J.B. Watson's (1925) seminal case for behaviourism as the only viable method for a scientific psychology; and it reverberates in the prominent contemporary idea that thoughts about the minds of others form a theory, a so called 'theory of mind'. At the core of this concept is the thought that mental states figure as theoretical postulates in an evolving theory for explaining overt behaviour. $^{2}$

The idea that other minds are essentially unobservable is, however, far from universally accepted. G.E.M. Anscombe famously claimed that we can see people's actions. Very early on in her Intention, Anscombe says,

I am sitting in a chair writing, and anyone grown to the age of reason in the same world would know this as soon as he saw me, and in general it would be his first account of what I was doing; if this were something he arrived at with difficulty, and what he knew straight off was how I was affecting the acoustic properties of the room (to me a very recondite piece of information), then communication between us would be rather severely impaired. (Anscombe 1957: 8)

\footnotetext{
${ }^{2}$ See Davies and Martin 1995 for an introduction to this concept.
} 
Anscombe's thought in this passage is that when asked to describe what another person is doing, the first description that will come to mind is (at least in many cases) in terms of what the person is intentionally doing. There is an open-ended number of things Anscombe could truly have been described as doing at that moment; 'affecting the acoustic properties of the room' is one such description. This would not be a description under which what she's doing is intentional, to use Anscombe's own phrase. 'Sitting in a chair writing', however, is such a description; and it is, on her view, also what most people would say that she was doing just from seeing her. Anscombe, then, claims that people's actions are a part of the observable world.

Now, when we describe what people are intentionally doing, are we describing aspects of their minds? Jennifer Hornsby, a philosopher building on Anscombe, argues that the answer is yes. She says that 'one is not in a position to take a view of which things are intentionally done by people unless one has some view of their mental states' (Hornsby 1997: 127). The idea here is that a description of a person's intentional action (a description under which the action is intentional), such as 'Peter is doing the dishes' or 'Sara is practicing her guitar skills', is not a description that is neutral with respect to how the person conceives of her situation and what her goals are in the situation. Making a judgment to the effect that 'Sara is practicing her guitar skills' is to be committed to Sara's having certain psychological properties: primarily the psychological property of taking herself to be practicing the guitar.

The quote from Hornsby does not present a complete argument for the observability of mental states. It just states a conditional: If we see what people are intentionally doing, then we see aspects of their minds. A traditionally minded epistemologist could just use the conditional to deny that we see intentional actions. That is, she could say that given that we don't see psychological properties, we cannot see actions either. She could advance the suggestion that a judgment such as 'Sara is practicing her guitar skills' ought to be thought of as having two components corresponding to two different sources: one is the direct perception of Sara's bodily movements - perceived as it were purely, not under any psychological aspects or presupposing psychological concepts - the other is a thought about the origin of those bodily movements based on an inference from those bodily movements to the representations and aims that might have produced them. 
This two-component picture of our thoughts about the actions of other people is powerful, and I do not aim to provide a convincing argument against it here. My aim here is not to argue for the perceptibility of other minds. But one thing to note is that the epistemological assumption under the pressure of Anscombe and Hornsby's supposition that we do see people doing things and thus see how they represent the world - has now taken on the shape of a substantive philosophical thesis about what it is that we really see, and what we then can make of what we see. It is no longer a self-evident starting point. This thesis can then be contested both by questioning whether pure bodily movements are actually within the range of things people can see, and if they are, whether such perceptions would give us any basis for supposing that the movements have the specific mental origins that we take them to have. ${ }^{3}$

Another area where the traditional assumption has been questioned recently is with respect to expressions, in particular emotional expressions. ${ }^{4}$ Expressions of emotions make, according to some contemporary authors, the mental states they are expressions of perceptible. Such a view is put forward by Mitchell S. Green in the monograph Self-Expression from 2007. There he points out that,

[We] often suppose not just that we can determine that a person is in a particular state of feeling; we also take ourselves to be capable of observing those feelings with one or more of our senses. We see the elation spread over one person's face as they comprehend the excellent news; we hear the impatience in another person's voice as they try to correct our misunderstanding; we feel the exuberance in a friend's robust handshake. (Green 2007: 24)

Similarly to the claims I quoted from Anscombe and Hornsby, these observations are not yet complete arguments against the traditional epistemological assumption. They merely point out that we seem, at least in some situations, not to care much for this assumption in the way

${ }^{3}$ See the same essay from Hornsby (1997: 93-111) for a critical discussion of the appeal to bodily movements in the epistemology of other minds.

${ }^{4}$ Not all expressions, it is plausible to think, are intentional actions. Think about a spontaneous outburst of laughter or a sudden grimace in response to a revolting smell; such things don't seem to be done on purpose. Hence it is another area, rather than a subset of the first. One could in fact argue that expression should be thought of as the broader category that encompasses intentional actions. For a suggestion in this direction, see Finkelstein 1999: 92. 
we ordinarily describe our cognitive grasp on other people's thoughts and feelings.

Green offers a framework for fleshing out these observations (and thereby, as I understand him, to begin to vindicate them). He thinks that we can observe another person's emotion in its expression by that expression being a part of the emotion it expresses. Just as the facing side of an apple - being a part of the apple - enables a person to perceive (not just the facing side of the apple, but) the apple, a smile, being a part of an emotion of happiness, enables a perceiver to see that someone is happy. Green says,

Someone who presents to me an apple from one angle has thereby shown me an apple even if I do not inspect its interior or its other side. The reason is that a sufficiently large portion of a side of an apple is, for normal human observers, not only itself perceptible but also a characteristic component of the apple. (Green 2007: 86)

If we're in the spirit of worrying about our access to other minds, we will find this analogy troublesome. An apple is a thing, and we can take a look at its other side or 'inspect its interior' should we please. But if we think of an emotion as a thing, and its expression as a part of this thing, we appear to be barred in principle from seeing its other parts (the parts that might seem to be the most essential). And we might then be inclined to re-iterate the traditional worry: don't we somehow have to base our knowledge on an inference from the part that we do see, to the other parts that we can't in principle see? ${ }^{5}$

But perhaps we don't need Green's particular version of the thought that we see emotions, if we find the analogy at its base unpalatable. An alternative image is provided by Rowland Stout, in an article where he invokes the idea of an Aristotelian process in order to articulate how an expression can make an emotion visible. His thought is that an expression is an actualization of a power, a process which realizes the emotion. He says,

${ }^{5}$ Green is not moved by this worry. He concedes that we cannot see all parts of an emotion, but that this is in fact not peculiar to the case of emotions. We can see galaxies, Green argues, even when we cannot in principle perceive the black hole in their middle. (Green 2007: 89) But a galaxy is a quite special 'perceptible object' and it is difficult to feel that it can provide the assurance we need. If people are like galaxies and their minds the unobservable black holes at their centres, knowing them appears to be a quite sophisticated and theoretically laden matter. 
The mental state is the disposition, potentiality, mechanism or power. It is realised, actualised or manifested in a process of facial expression or other behaviour. What is perceived is not just the upshot of the process, but the process itself; you see the emotion playing out in someone's face. This is like perceiving someone's strength in their handshake. Their strength causes the firmness of grip but it is not some prior event or state that has to be inferred from it. The strength is present in the handshake. The cause is manifest in its effect. (Stout 2011: 137)

Stout argues that thinking of the expression of an emotion in terms a process of realization of a power can make proper sense of the thought that we can perceive emotions in their expressions. For the expression is now not conceived of as a thing or event, separable from the event of the emotion. Neither is it thought of as a part of a composite thing or event. Rather, the expression is thought of as a stage in a process which is the emotion, being realized. ${ }^{6}$ This strikes me as a prima facie more appealing picture than Green's of how it is that we can see another person's emotion in its expression. But it requires that we accept that an emotion is a disposition and an expression its actualization; a thought we might find it difficult to swallow.

It is, however, also possible to reject the question that both Green and Stout appear to feel the need to answer: what is the metaphysics of mental states and behaviour such that we can see the former in the latter? We can argue that the thought that we can sometimes see what another person is, say, intending or feeling, can get traction without any general view of the nature of mental states and behaviour. All we need, from the perspective I'm now considering, is the thought that mental concepts are bound up with circumstances in our shared world. And in learning to use those concepts, facts about people's intentions and feelings come within the reach of our conceptually informed experience. No metaphysical account of the relation between mental states and behaviour - of the sort articulated in Green's idea that expressions are parts of emotions or Stout's idea that emotions are dispositions realized in behaviour - is then required. This would be to think of expressions and actions as conceptually related to states of mind, but not necessarily in the simple

${ }^{6}$ To fully make sense of the thought that expressions make emotions perceivable, Stout thinks we need to couple the thesis that the expression of an emotion is a process with the idea that acts of perceiving likewise are processes. 
or uniform manner suitable for a general account. Arguably this is, in outline, the view of the later Wittgenstein. ${ }^{7}$

The traditional epistemological assumption that other minds cannot be observed has, then, alternatives. ${ }^{8}$ The question is whether accepting such an alternative also means that we have to give up the traditional idea that knowledge of other minds is special. If we embrace the idea that other minds are indeed a part of our common, shared, and observable world, does this mean that knowledge of another person is just like knowledge of the movements of the clouds in the sky, the process of a tree falling to the ground, or the currents of rivers? I think the answer is no, and I will spend the rest of the paper explaining why. I will argue that seeing people's actions and expressions, and thereby coming to know something about their minds, contains within itself the possibility of a form of knowledge that is different from perceptual knowledge of falling trees. This form of knowledge is radically peculiar to knowing another person.

\section{ACTION AND EXPRESSION AS ENABLING A COGNITIVE RELATION TO THE PERSON}

Imagine the following reaction to the preceding discussion about whether or not we can see other minds:

It is quite beside the point whether or not we can see other minds. The knowledge we gain from observing people and collecting facts about them is anyway not exemplary of what it means to know another person. To have 'access to another mind' does not mean to know something about a person, such as, 'This person is happy' or 'That person intends to move a heavy table. It means, rather, to have access to the person, of the sort we have when we're speaking to the person and understanding what they are saying. If we are interested in what it means to know another

${ }^{7}$ I do not intend this list of options for thinking about the perceptibility of other minds to be exhaustive. There is also, for instance, the entire phenomenological tradition and its ways of articulating this thought.

${ }^{8}$ We should be careful not to confuse the claim that it is possible to see what others are intentionally doing or what emotion they are expressing, with the thought that it is always easy to do so. It is often a quite difficult matter. The point is, rather, that when it is difficult to figure out another person's intention or feeling, say, what we have to go on in trying to interpret them is not psychologically neutral information about their bodily movements. 
mind, we should focus on describing what it is for two people to have access to each other in this sense. The debate about seeing or not seeing other minds is a red herring.

The aim of this section and the next is to elaborate this reaction (inchoate as it stands), and argue that, properly understood, we should take its suggestion to heart. I will do so first with the aid of a recent essay by Michael Thompson, and in the next section by turning to Stanley Cavell's notion of acknowledgment.

I start by quoting Thompson:

One human being comes upon another and perceives her doing something, or observes her at it - he is setting up a camera, she is crossing a road, he is moving a pump handle. The enquirer knows by perception, by an intuition or Anschauung of the other as other, by observation of her, that the agent is setting up a camera or is crossing a road.

[...] In the first instance this empirical knowledge is demonstrative and third person in character. But the difference between the observer's observational thought in the case at hand, and his thought in other cases of observed things happening, like trees falling down, comes next. The observer moves into what we might call a cognitive relation with the agent herself and asks her why she's doing it. He does not do this with falling trees. The mark of this cognitive relation is the use of the second-person, 'Why are you doing A?' That he addresses himself to the observed individual substance is already a clue that something is different. (Thompson 2011: 206)

The topic of this passage from Thompson is knowledge of another person's intentional actions. I want to highlight three claims he makes in it.

(1) Intentional actions can be known observationally.

(2) There's still a difference between an observational thought about someone's action and an observational thought about, say, a falling tree.

(3) The difference is that an observational thought about someone's intentional action contains the possibility of entering into a cognitive relation with the agent herself, a cognitive relation the mark of which is the use of the second-person 'you'. In asking the person 'Why are you moving the pump handle up and down?' we show that have entered into a cognitive relation to the person. 
The first claim is simply an endorsement of the Anscombe/Hornsby view described above: we can perceive people's actions. The second claim is that this is not all there is to our knowledge of another person's actions. The third claim describes the difference, and it is on that claim I want to focus. For understanding the third claim, the key phrase is 'enter into a cognitive relation with the person'. This cannot simply mean to come to know something about the person. We have that kind of cognitive relation to the falling tree as well. And this kind of cognitive relation was supposed to be different. So what could it mean?

Thompson doesn't directly state in this paper what he means by this phrase. But what he does say gives us a clue: The mark of this relation is a second-person address: 'Why are you doing A?' What is special about a second-person address? One feature of this form of speech is that it is directed at a specific person, and it invites this person to communicate. It does so with the presupposition that the person is in a position to recognize this invitation and respond to it appropriately. We might, then, conjecture that the cognitive relation with the agent Thompson has in mind here is one where, in the first instance, knowledge is somehow mutual or shared. In using 'you' in a question about what someone is doing, I both reveal to the person addressed what I already know about what that person is doing, and I invite the person to share with me something I do not yet know.

To have shared knowledge, on the way I want to use the phrase, is for two people mutually to recognize a piece of knowledge, and recognize it precisely as a mutual piece of knowledge. If you and I share a piece of knowledge, I know that you know, you know that I know, we both know that we both know that we know, etc. Using 'you' in an interrogative is to invite shared knowledge that has precisely this structure. But there's something else that pertains to the cognitive relation to the agent Thompson is concerned with. The question 'Why are you moving the pump handle up and down?' is addressed to the person as an agent, not as another observer.

What does this mean then? It has to do with the fact that we expect the person to answer not by gathering observational information, or by submitting observational information already gathered. The expectation is that the person already knows the answer to this question, and does so not by observation. Hence the shared knowledge prompted by the question 'Why are you moving the pump handle up and down' is different from the shared knowledge enabled by the question ' $\mathrm{Hey}$ you, why is that 
tree falling down?' (Unless, perhaps, the tree is a part of the scenography for a play, the addressee is the scenographer, and is thus in charge of making sure the trees are positioned correctly.) Another way of putting this thought (that the expectation is that the addressee can answer the question without observation) is that the question is an invitation for the person to articulate her self-conscious knowledge.

Thompson's third claim was that the difference between an observational thought about a falling tree and an observational thought about a person's intentional action is that the latter contains the possibility of entering into a cognitive relation with the agent. This claim can, then, be glossed as the idea that the difference is that the observational thought in the case of the falling tree is not a first step towards shared knowledge where one person is articulating her self-conscious knowledge. I cannot share a piece of knowledge about the falling tree with the tree, and if I do share it with another person, I share it with the other person as another observer. ${ }^{9}$

Having arrived at this gloss on the claims from Thompson I'm interested in, I will suggest that the three claims he makes can be transposed from the case of seeing another person's intentional actions to the case of seeing another person's expressions. Think about the case of Peter's happy smile. If we go along with Green's and Stout's views, I can know that Peter is happy just from seeing his happy smile. And I might also see why he's happy, such as when he is joyfully smiling when he's playing with his newborn baby. But I might also not see why Peter is happy, such as when he is thinking to himself and suddenly smiles. And in such a case, I do well to ask Peter, 'Why are you so happy' or 'What are you smiling about?' In asking these questions I don't address Peter as a fellow observer, rather, I expect to be able to expand my knowledge of the situation just from receiving Peter's self-conscious articulation of what he's happy about. The second-person address is an invitation to Peter to articulate his state of mind, and in this way to share with me a piece of knowledge.

It is, of course, not the case that all expressions elicit a second-person address, and thus move to the stage of shared knowledge, rather than

9 The point in stressing the linguistic address and response is not, as I understand it, to claim that shared knowledge needs to be actually verbally articulated in each case. A mutual look might in a situation suffice to establish shared knowledge. The point, rather, is to claim that the knowledge is articulable. Therefore the cases where it is actually articulated are exemplary. 
mere knowledge of a fact about the person. We usually don't address strangers in this way. But the reason why we don't is social and conventional. It would be unexpected and perhaps intrusive to ask a stranger laughing about something as you pass him in the street: 'What are you laughing about?', but it would be a comprehensible question. It would not be a comprehensible question, at least not if someone claimed to intend it as a real address, to ask a tree why it is falling. The fact that people's expressions can confront us with the question of whether our relation to the person is such as to warrant a second-person address is itself a significant datum. Faced with someone's expression we can ask ourselves: is this someone it is socially acceptable for me to address, is it someone I'm expected to address, or is it even someone I'm obliged to address (because not addressing the person would be insensitive or cold)? Falling trees are not eligible to be placed on the scale that ranges from the strangers to the intimates. (I will come back to this thought in the next section on Cavell.)

The thought, then, we get from transposing Thompson's claims to the realm of expressions is that when we come to know that someone is happy from seeing her happy smile, the thought: 'She's happy' is the first step to entering into a cognitive relation with the person. This is not the relation of a knower to an object known but of a knower to another knower, a person who has the capacity to self-consciously articulate her own states of mind. When we come to know that a tree is falling from seeing the falling tree, we are not in the first stage towards a cognitive relation of this kind with the tree. This, I think, tells us something significant both about expressions and about knowledge of other minds.

If expressions can yield perceptual knowledge of another mind, this piece of knowledge, by contrast with perceptual knowledge of other things, contains within itself the possibility of a second-person address a question using the second-person pronoun 'you'. A rash on one's arm makes one exposed as someone whose allergic reaction is there to be known. And a sneeze makes one exposed as someone whose cold is there to be known. But a joyous smile or a puzzled frown makes a person exposed as someone with knowledge to share.

\section{CAVELL AND ACKNOWLEDGMENT}

According to the picture I've sketched, action and expression enable a cognitive relation to a person, and this is a type of knowledge crucially 
different from merely knowing something about a thing (such as knowing that the tree is falling from seeing it fall). In describing this relation, with Thompson, as a cognitive relation, we should not be misled into thinking that this relation is devoid of emotional and practical significance. A puzzled frown makes someone exposed as someone who can be addressed with the question: 'What are you puzzled about?' but this question is, in the paradigmatic case, a concerned question. It is one that, say, signals recognition of a frustration and a preparedness to, if possible, provide an explanation of an unclear remark. (This is only an example; what people might want or need from another person in a situation where they are expressing their emotions is of course quite situation and person specific.) Stanley Cavell offers a concept for a cognitive relation to a person of the sort outlined in the previous section, namely acknowledgment, and he highlights its emotional and practical dimensions.

In his essay 'Knowing and Acknowledging', Cavell offers a reinterpretation of the problem of other minds in the form it takes within the analytic philosophical tradition. One result of his re-working of the problem is the thought that other minds are special not in that they are particularly difficult to know (because, say, their properties are perpetually hidden from view), but in that the knowledge we're primarily interested in when it comes to other minds is of a peculiar sort. Cavell calls this form of knowledge acknowledgment. ${ }^{10}$

Cavell's starting-point in this essay is slightly different from mine. I started by examining the assertion and denial of the claim that psychological features of people are a part of the public observable world. The issue he, on his part, spends most time on is the sceptical dialectic starting from the idea that we cannot have (or feel) another person's pain. ${ }^{11}$ But his diagnosis of this dialectic can be of use for our

${ }^{10}$ This thought was, of course, not a 'new' thought in the history of philosophy. Arguably (by people more historically versed than I am), versions of it can be found in for instance Hegel and Fichte, and perhaps also in Levinas. But Cavell's aim in this essay is to diagnose a certain dialectic within the then current analytic philosophical discussion about other minds. New incarnations of this dialectic keep cropping up, and the discussion about whether or not we see other minds is one example. Given my interest in this discussion, I find that Cavell's framework for articulating that thought is particularly useful.

11 'The sceptic' is in Cavell's thought not a particular philosopher or a representative of a doctrine. The sceptic is, rather, a conversation partner, someone whose position Cavell tries to occupy in order to give voice adequately to a progression of thought. 
problem. What he argues is that even if we try our best to give the sceptic what he says that he wants, namely to imagine a situation where two people can have each other's pain, it would be a disappointment to the sceptic. It would not be exemplary of knowing another person's mind. One way of putting what such a situation would lack is the possibility of a mutual address using the second-person 'you'. Two people who had each other's pains would not be separate in the sense required for being able to respond in this way to the pain of the other. They could not say, for instance, 'Is there anything I can do to help you?' and mean any of the things we might mean by saying such a thing. ${ }^{12}$

What does it mean to give the sceptic what he says he wants, one might wonder? The way Cavell proceeds is by considering a thought experiment, adapted from Alexandre Dumas' novella The Corsican Brothers. In Cavell's version of the story, the two brothers, First and Second, have a peculiar bond. Whenever First feels pain, Second feels it too. Even when miles apart, Second feels pain in exactly the same place and with the same intensity as First does. Moreover, Second never feels pain unless First does. Second doesn't scream or grimace when he cuts himself; he hurts only when something has happened to First. Second's pain is also a direct effect of First's, there's no damage on Second's body in connection with the episodes of pain.

Cavell suggests that what we have here comes close to imagining a situation where two people feel the same pain. (There are, of course, a number of question-marks regarding what we are asked to imagine and whether we can form a coherent image on the basis of these premises. But if we dig in our heels too early, we'll miss an important lesson.) Not only do Second and First have qualitatively the same pain - like two people who suffer from the same kind of headache - they have numerically the same pain. The sceptic ought, then, to be satisfied with the epistemic positions of the Corsican Brothers; they should be a good illustration of why our ordinary position with respect to each other is so frightfully inadequate. But, Cavell argues, they are not. Turning to the epistemic positions of First and Second respectively, Cavell wonders whether First's knowledge of Second's pain is of the kind that the sceptic appears to be asking for. The answer, Cavell thinks, is that First's position with

${ }^{12}$ Cavell's essay is critical of the way in which some of his contemporaries - exemplified by Norman Malcolm and John W. Cook - invoke ordinary language to refute the sceptic, while it tries to exemplify a different version of ordinary language criticism. 
respect to Second's pain doesn't look much better on inspection than our ordinary position with respect to others; it might even look worse.

It might look worse because the primary fact for First when he is in pain is that he is in pain. The thought might strike him that Second is in pain too, but it also might not. He might forget this in the midst of his own suffering. And even if he does remember, First is not in a particularly good position to respond to Second's pain, since he is preoccupied with his own precisely during and to the same extent as First is, and hence is not the best person to respond to Second's pain. Cavell writes: 'Every pain First feels is his. (This now means something in contrast to Second, none of whose feelings are his.) First knows what Second feels (and when and where he is feeling it) - but so can we know those things.' (Cavell 1969: 252)

But what about Second's epistemic position? The problem here is that Second is not relevantly other to qualify for the description knowing another person's pain'. Since Second has no pain of his own, he can as well express pain by saying 'I feel pain' as by saying 'He feels pain'. And, most importantly, we're not quite sure what it would mean for Second to say to First: 'You are in pain.' It would hover between an expression of his own pain (Second's), and a response to First's. The distinction between the two individuals is, in this respect, blurred, and hence the possibilities for expression and response undercut. Hence Second's knowledge isn't quite knowledge that another person is in pain. Cavell says,

$[H]$ is pain no longer contrasts with $m y$ pain, his has no further content, so to speak; 'his pain' no longer differentiates what he feels from what I feel, him from me; he is not other in the relevant sense. (Cavell 1969: 253)

If First's position is not any better - or even worse - than ours with respect to Second's pain, Second is not quite in a position to even know, or respond to, First's pain as another person's pain. So even though the sceptic thought that feeling another person's pain was the requirement needed to really know another person's pain, it turns out that even this wouldn't satisfy him.

An intrinsic part of why this thought experiment is disappointing for the sceptic is because it removes the conditions for a genuine secondperson address. The Corsican Brothers are not exemplary cases of knowing another person's pain partly because they are not in particularly good positions to judge 'You are in pain' as a response to the other person's pain. For First, this is because 'I'm in pain' is the primary fact for 
him, for Second this is because he is not relevantly separate from First. Cavell articulates two questions on the basis of the thought experiment:

But how shall we understand this wish for a response to my expressions (of pain, of any region of the mind)? Does it suggest that our concept of my knowledge of another is bound up with the concept of my freedom, an independence from the others, from all others - which I may or may not act upon? (Cavell 1969: 253)

Cavell's response to the first question is to propose the concept of acknowledgment. And the answer to the second question his essay implies is yes. What leads Cavell to say that the concept of knowledge when we are considering other minds is different from the concept we use when we are talking about knowledge of mere objects, is that an exemplary expression of knowledge of another person is a concerned response to the person.

We can note, first, that the Corsican Brothers do not have what I have above called shared knowledge. Shared knowledge, as I characterized it, was knowledge that required two people's mutual recognition of each other. It is marked by the use of the second-person, such as in saying, 'Is there anything I can do for you?' Just by their situation, the Corsican Brothers do not have shared knowledge. It is, moreover, not clear even that they can have shared knowledge in precisely this sense, since 'You are in pain' in Second's mouth, as we said, can't exactly mean what it means for us. If we return to the theme of the very first section of this paper, there is no such inherent tension between the idea of seeing another person in pain, and having shared knowledge. But seeing is not sufficient for shared knowledge. I might see that 'This person is in pain' but unless I've responded to the person this knowledge is not shared. And shared knowledge, as I understand Cavell's point, is one way of describing the different concept of knowledge we have when other minds are concerned. If we remain at the level of the judgment 'I see that this person is in pain' we will not have captured in full what knowing another person means. We need to see that such a judgment contains the possibility of the response 'You're in pain, can I do something for you?' to get the concept fully in view.

Expressions, Cavell says in the quote above, come with a wish for a response. The response it wishes for is at once an expression of knowledge, and an act of concern towards the person. 
It is not enough that I know (am certain) that you suffer - I must do or reveal something (whatever can be done). In a word, I must acknowledge it, otherwise I do not know what '(your or his) being in pain' means. Is. (Cavell 1969: 263)

Acknowledging someone's suffering, Cavell claims in this passage, is to do or reveal something. Expressing compassion by saying 'I know you are in pain' is one example of an acknowledgment. But we ought not to be under the impression that acknowledgment is the tag for a specific mode of response to another person, namely being empathetic or compassionate. And it would be odd to claim that we must be compassionate with suffering people, even if we hear the 'must' as an ethical ought. Clearly we are in fact not always compassionate, nor is it clear that we always ought to be. Cavell's point is, rather, that knowledge of another person takes, paradigmatically, the form of knowledge that you are, say, suffering - and this means that the question how do I respond to you is always relevant. It is always on the table. When the knowledge is shared, in the sense outlined above, there is no escaping the relevance of what we do, say, and feel, in response to the person. Cavell explains,

So when I say that 'We must acknowledge another's suffering, and we do that by responding to a claim upon our sympathy', I do not mean that we always in fact have sympathy, nor that we always ought to have it. The claim of sympathy may go unanswered. We may feel lots of things - sympathy, Schadenfreude, nothing. [...] [Acknowledgment] is not a description of a given response, but a category in terms of which a given response is evaluated. (Cavell 1969: 263)

We can understand Cavell as saying, then, that an expression (of pain, say) calls for a response in the form of an acknowledgment, and this makes it the case that whatever one does in response, even if nothing, can be described and evaluated with respect to this call for an acknowledgment. And issuing an acknowledgment is, as I understand the concept, precisely what one does when one enters into a cognitive relation to a person in the way I've described here. An acknowledgment takes the form of a secondperson address, and it addresses the person not as a fellow observer but as a person who can self-consciously articulate her own states of mind. But it also addresses the person as someone who is possibly in need. What an expression potentially shares is not merely knowledge, but also circumstance, or plight. 
Does this mean that I (and Cavell) think that knowing another mind is intrinsically an ethical matter? It does, if what this means is simply that shared knowledge makes two people vulnerable to the needs, wants, and requests of each other, and so subject to the specific forms of evaluation that attaches to such vulnerability. Given that expressions open oneself to a cognitive relation with another person, an ethical claim might always present itself, say in the form of a recognition of a need.

Now, as the argument of this paper is structured it might be thought that I think of the cognitive and the practical/emotional response as two stages in a process. This is not the image I wish to convey. The idea is not that shared knowledge comes first, and then comes a practical and emotional response. Rather, I would argue that a central characteristic of coming to a shared knowledge is that it is at once cognitive, emotional, and practical. It is expressed in a concerned question: 'What's that smile?' or 'How are you doing?'

One important consequence of thinking that knowledge of other persons can take the form of acknowledgment - shared knowledge that makes two people exposed and vulnerable to each other - is that we also note that this form of knowledge has its own anxieties and difficulties. (Considering the different aspects of this consequence is a persistent theme in Cavell's writings, in particular in Part IV of The Claim of Reason (1979).) There is no guarantee that a person will open up to me and share his knowledge with me by articulating what he is thinking or feeling, and there is no guarantee that if I open up I will get the response that I wished for. In this region of the concept of knowledge, we run up against the independence, frailty, and even potential cruelty of the other. In the face of these specific difficulties, it is no consolation whatsoever to point out that I can see what the person is thinking or feeling. Mere observational knowledge, if divorced from the possibility of acknowledgment, doesn't give me what I want; it doesn't correspond to my real interest. This is, we might think, a way of expressing an insight in the tradition of denying that other minds can be observed. What we can see is not by itself enough; we want the kind of knowledge that only comes with a mutual cognitive relation to the person. If we're interested in giving an account of the way action and expression afford knowledge of other minds, this line of reasoning should make us qualify the idea that they enable perceptual knowledge of another mind. They do so, but they also and more importantly enable a cognitive relation between two people of the kind marked by an acknowledgment. The insight in the 
epistemological tradition of thinking that other minds are special can, then, be formulated as follows: Happy people and falling trees can both be seen but only the former can be acknowledged. ${ }^{13}$

\section{BIBLIOGRAPHY}

Cavell, Stanley. 1969. 'Knowing and Acknowledging', in Must We Mean What We Say: A Book of Essays (Cambridge: Cambridge University Press, repr. 2002), pp. 238-266

Cavell, Stanley. 1979. The Claim of Reason: Wittgenstein, Skepticism, Morality, and Tragedy (Oxford: Oxford University Press)

Churchland, Paul. 1988. Matter and Consciousness: A Contemporary Introduction to the Philosophy of Mind (Cambridge, Mass.: MIT Press)

Davies, Martin and Tony Stone, eds. 1995. Folk Psychology: The Theory of Mind Debate (Oxford: Blackwell)

Finkelstein, David. 1999. 'On the Distinction Between Conscious and Unconscious States of Mind', American Philosophical Quarterly, 36: 79-100

Green, Mitchell S. 2007. Self-Expression (Oxford: Oxford University Press)

Hornsby, Jennifer. 1997. Simple Mindedness: In Defense of Naïve Naturalism in the Philosophy of Mind (Cambridge, Mass.: Harvard University Press)

Russell, Bertrand. 1948. Human Knowledge - Its Scope and Limits (London: George Allen and Unwin)

Stout, Rowland. 2012. 'What Someone's Behaviour Must Be Like in Order to Perceive Their Emotions In It', Phenomenology and the Cognitive Sciences, 11 (2): 135-148

Thompson, Michael. 2011. 'Anscombe's Intention and Practical Knowledge', in Essays on Anscombe's Intention, eds Anton Ford, Jennifer Hornsby, and Frederick Stoutland (Cambridge, Mass.: Harvard University Press), pp. 198-241

Watson, John B. 1925. Behaviorism (London: Kegan Paul)

${ }^{13}$ I presented a short version of this paper at the conference The Second-Person Perspective in Science and the Humanities, Oxford 2013. I'm grateful to the participants of this conference for valuable comments and discussion. In particular I want to mention Monika Dullstein. Her presentation had affinities with mine and I've benefited greatly from conversations with her. The paper was also much improved by comments on a previous draft from Ulrika Björk, Martin Gustafsson, and the editors of this volume. My work on this essay has been supported by the Kone Foundation and the Academy of Finland. 